\title{
GRID SIDE REGULATION OF WIRELESS POWER CHARGING OF PLUG-IN ELECTRIC VEHICLES
}

\author{
John M. Miller, Clifford P. White, Omer C. Onar \\ National Transportation Research Center \\ Oak Ridge National Laboratory \\ Knoxville, TN USA \\ millerjm@ornl.gov
}

\author{
Philip M. Ryan \\ Fusion Energy Division \\ Oak Ridge National Laboratory \\ Oak Ridge, TN USA
}

\begin{abstract}
Conductive charging of plug-in and battery electric vehicles (PEV's) is now well established and becoming more pervasive in the market. Conductive charger regulation of vehicle regenerative energy storage system (RESS), or battery pack charge rate is controlled by the dedicated onboard-charger (OBC) in coordination with the vehicles battery management system (BMS). Wireless Power Transfer (WPT) charging of PEV's is a relatively new and emerging technology that will not benefit from standardization work until 2014 or later. As such, various approaches are currently underway to manage the power flow from the grid-tied high frequency power inverter to the vehicle RESS. WPT regulation approaches can be secondary side only, primary side only or a combination of both. In this paper Oak Ridge National Laboratory (ORNL) envisions a system that is fast charge compatible and that minimizes the vehicle on board complexity by placing the burden of power regulation on the grid side converter. This paper summarizes the ORNL approach and experimental lessons learned at the National Transportation Research Center WPT laboratory ${ }^{1}$.
\end{abstract}

\section{INTRODUCTION}

Wireless Power Transfer (WPT) is emerging as a safe, convenient, flexible and autonomous charging method for plug-in and battery electric vehicles (PEV's). It is safe because the vehicle is inherently isolated from the grid connection via the large gap between WPT transmit pad and vehicle mounted receiver coil. This means that wireless charging can be done during inclement weather without need of bulky cable and heavy duty plugs. WPT charging is convenient and flexible not only because no cables and connectors are necessary but due more to the fact that charging becomes fully autonomous. This is possibly the most convenient attribute of WPT because PEV charging can be made fully autonomous so it may eventually eclipse

Notice: This manuscript has been authored by UT-Battelle, LLC, under Contract No. DE-AC05-00OR22725 with the U.S. Department of Energy. The United States Government retains and the publisher, by accepting the article for publication, acknowledges that the United States Government retains a non-exclusive, paid-up, irrevocable, world-wide license to publish or reproduce the published form of this manuscript, or allow others to do so, for United States Government purposes. conductive charging. As the technology evolves it is not difficult to imagine a vehicle with magnetic field sensing or a parking aide being capable of positioning itself over a primary pad for optimum alignment and autonomous charging. Vehicle to infrastructure (V2I) communications adds to the autonomy benefit by handling all the bidirectional communications needed for charging transactions as well as providing the feedback channel for power flow regulation. The system level diagram of ORNL's primary side regulation is shown as Fig. 1.

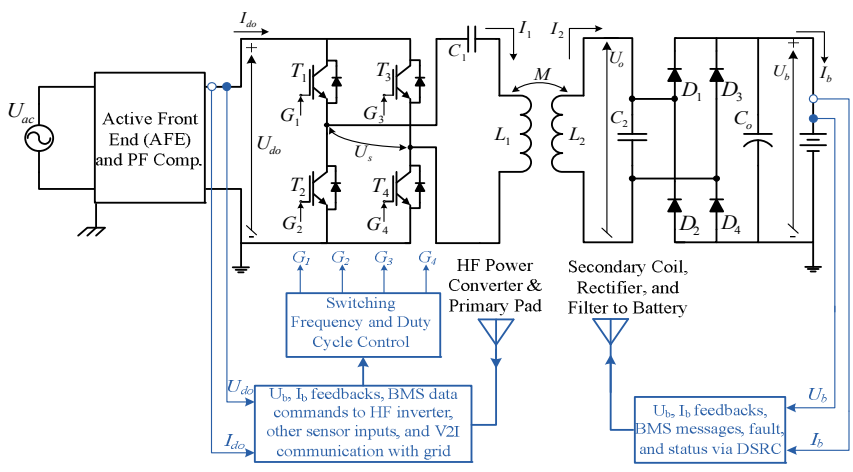

Figure 1. Wireless Charging having primary side regulation facilitated by a radio in the communications path

From a commercialization perspective there should be parity in the charging efficiency of WPT and conductive charging systems. At present, being on par with conductive charging implies $85 \%$ to $90 \%$ overall efficiency between the grid connection and the vehicle battery pack. The primary contributor to this goal is coil to coil efficiency on the order of $96 \%-97 \%$ and the high frequency (HF) power inverter in the same range. Add to this the need for active front end power factor correction, harmonic filtering and noise suppression, then it should be no surprise that the WPT components integrated to the vehicle must be $96 \%$ to $97 \%$ efficient on average (i.e., a 4-block cascade yields $0.96^{4}=0.849$ to $0.97^{4}=0.885$ ). This is one reason why ORNL advocates primary side only regulation so that the electronic content added to the vehicle is an absolute minimum, and the lowest cost alternative. Vehicle to infrastructure, V2I, communications completes the hardware needed on the 
vehicle. This however is minor in comparison with any power electronics that would be needed for secondary side only regulation. Primary side regulation is also forward compatible with future fast charging standards, such as equivalent dc fast charge at $45 \mathrm{~kW}$ or higher. The remaining WPT regulation alternative is to implement some combination of primary plus secondary based electronics. For example, the grid tied converter could be coarsely regulated to meet the input dc voltage requirements of a dual use (e.g., a 4-port, vs. today's 3-port) on-board-charger (OBC). The OBC in turn would perform final regulation of the WPT input power to match the vehicle regenerative energy storage system (RESS) requirements.

ORNL researched published literature on key aspects of wireless and inductive power transfer relevant to an internal program mandate to demonstrate $7 \mathrm{~kW}$ charging (SAE level 2) of a plug-in hybrid electric vehicle (PHEV). In [1] the authors describe a secondary coil design used to mate with a roadway embedded primary cable. In one implementation this group found that operating at $20 \mathrm{kHz}$ and over a $10 \mathrm{~mm}$ air gap between the primary cable at $100 \mathrm{~A}$ and secondary coil it was possible to transfer $3 \mathrm{~kW}$ at $80 \%$ system efficiency. Primary plus secondary side control has been critiqued [2] and summed up in one sentence by those authors as: "However, application of two controllers in both input and output sides will not only increase the cost but also render the system less reliable." ORNL subscribes to this same philosophy and advocates primary side control of WPT for the same reasons, including the desire to minimize vehicle complexity. The authors in this reference also found that as secondary load changes the operating frequency must be adjusted. In [3], a companion paper to [2] the same authors delve deeper into primary side control but focus mainly on light loading conditions, a case that will present itself when the secondary coil is absent (to be covered here in a later section). Their main contention however is that soft switching power inverter methods aimed to improve system efficiency were not found to be highly effective. This reinforced ORNL's philosophy to keep the HF power converter and coupling coil tuning as simple and direct as technically possible. Mecke and Rathge [4] do focus on soft switching power inverter but offer suggestions on use of higher frequency, for example $50 \mathrm{kHz}$ for large air gap WPT. They point out that with a soft ferrite backed coil, $400 \mathrm{~mm}$ in diameter, and a Litz cable winding that power could be transferred across $300 \mathrm{~mm}$ gap at $>80 \%$ efficiency. Simultaneous high power over a $200 \mathrm{~mm}$ gap at high efficiency remains a significant challenge. The authors in [5] discuss the achievement of $90 \%$ efficiency over a 100 $\mathrm{mm}$ gap and apply this to automated guided vehicles. Additional technical content in $[6,7,8,9]$ are consistent with the citations discussed, but provide further elaboration on key aspects of WPT. For example, in [6] the authors note that when $0.1<\mathrm{k}<0.5$ that operation should be from $10 \mathrm{kHz}$ to $50 \mathrm{kHz}$. The authors in [7] provide examples of weight reduction by minimization of ferrite use. This is an important guideline in light weighting the vehicle mounted secondary coil. The findings in [8] reinforce the point that as load changes the resonance point changes, but the authors there are recommending operation $15.9 \mathrm{MHz}$, a radiating frequency that is not of interest in WPT vehicle charging at this time. A departure from conventional coupling coil design is highlighted in [9] where the authors suggest use of multiple coils forming a WPT system. Of importance to us is that these authors point out the distinction between circular and polarized pads noting that if a non-polarized circular coil equipped vehicle parks over a polarized primary pad that power will be lower, more fringing flux will be present and significant leakage results. These same authors in a companion paper [10] offer a coupling coil solution they refer to as the DDQ design for double-Dquadrature that is claimed to offer a larger charge zone (i.e., tolerant of misalignment) and that is compatible with nonpolarized circular coils. These same authors view EV applications for WPT as needing a $2 \rightarrow 7 \mathrm{~kW}$ power level over an air gap of $100 \mathrm{~mm}$ to $250 \mathrm{~mm}$, with a practical design being $7 \mathrm{~kW}$ over $125 \mathrm{~mm}$ gap and suitable for EVs. Finally, the system described by Budhia, Covic and Boys [11] is very interesting to WPT research because the authors discuss making use of EM field finite element analysis, FEA, to guide coupling coil design. They describe a $2 \mathrm{~kW}$, $700 \mathrm{~mm}$ diameter pad capable of $130 \mathrm{~mm}$ misalignment when operating over a $200 \mathrm{~mm}$ air gap. Additional insights are to be found in the excellent work of $\mathrm{Wu}$, Gilchrist, Sealy, Israelson and Muhs [12]. With this background the ORNL team proceeded with detailed coupling coil design, fabrication and experimental validation.

\section{COUPLING COIL DESIGN}

In WPT systems the coil design is the most important element in the overall system because it determines the power transfer level, and to a large extent the overall performance and efficiency, plus the shielding and magnetic emissions levels to be expected. The ORNL coil design relies on Litz cable coils over a soft ferrite structure and a non-magnetic case having very low profile. Fig. 2 illustrates an adjustable fixture fabricated for a primary and secondary coil pair wound with 7 turns of $5 \times 1250 \times 38$ AWG (i.e., 5 in hand) jacketed Litz cable.

Electromagnetic design of WPT coupling coils provides the most fundamental investigation into their performance. In [13] the author develops the magnetic vector potential due to an ideal primary coil at a field point that lies at the location of the secondary coil. For a coil pair having a radius a, assuming infinitesimal conductor radius, and a coil to coil spacing, $z$. Then the radius from the primary coil origin to the field point is $\mathrm{r}=\sqrt{\left(a^{2}+z^{2}\right)}$ and vector potential, $\mathbf{A}_{\phi}$, for a case of $\mathrm{N}_{1}$ primary turns and $\mathrm{I}_{1}$ Amps yield a primary excitation of $\mathrm{N}_{1} \mathrm{I}_{1}$ amp-turns. This primary excitation is depicted as Idl in Fig.2. 

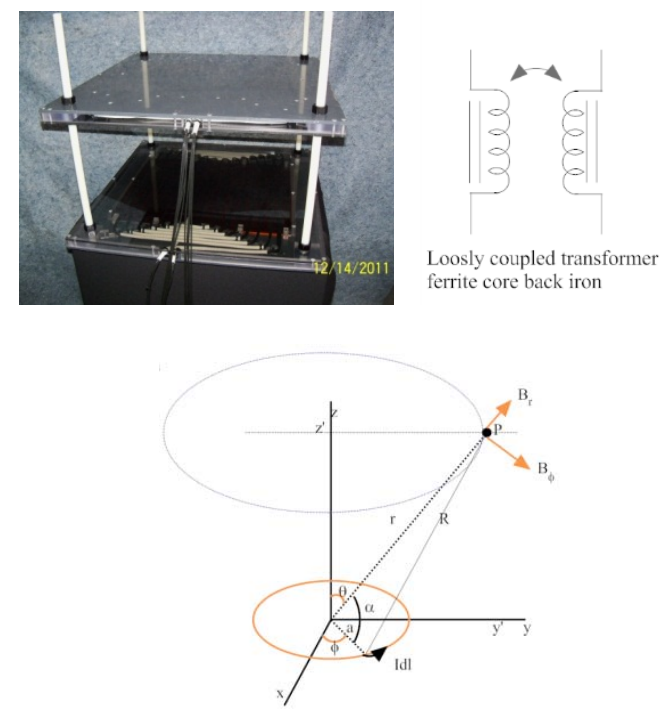

Figure 2. Experimental fixture with 7 turn distributed Litz winding, coupling coil symbol, and vector field analysis diagram.

\section{A. Sensitivity of Coupling Coefficient with Coil Size}

Referring to the vector field analysis diagram provided in Fig. 2 it can be seen that at the field point, P, the vector potential $\mathbf{A}_{\varphi}$ will be constant along the contour shown for which (1) applies. This contour can then be recognized as the envelope of a flux tube emanating from the primary coil.

$$
A_{\varphi}=\frac{\mu_{0} N_{1} I_{1} a_{1}^{2} \sin \theta}{4 r^{2}}
$$

At the field point, $\mathrm{P}$, the magnetic vector potential is strongly dependent on primary coil radius, total current, the co-elevation angle, $\theta$, and inverse with separation distance, $\mathbf{r}$, squared. However, it is the flux density, $\mathbf{B}(\mathbf{r}, \theta)$, and total flux, $\phi$, at the secondary coil that is most relevant to WPT performance. Taking the curl of $\mathbf{A}_{\varphi}$ leads to the radial, $\mathbf{r}$, and co-elevation, $\theta$, components of flux density, $\mathbf{B}(\mathbf{r}, \boldsymbol{\theta})$. Note in particular the near field $1 / \mathrm{r}^{3}$ dependence of flux density in (2).

$$
B(r, \theta)=\hat{r} \frac{\mu_{0} N_{1} I_{1} a_{1}^{2}}{2 r^{3}} \cos \theta+\hat{\theta} \frac{\mu_{0} N_{1} I_{1} a_{1}^{2}}{4 r^{3}} \sin \theta
$$

The radial component of the field point flux density can be interpreted as the "fountain" field and the co-elevation portion as the "flat" field. These terms become important when considering the design of multiple primary coils comprising an energized track as may be used for dynamic, or in-motion, wireless power charging. In this paper the meaning of (2) will be interpreted differently and used to obtain a key design criterion of WPT coil design, that of the influence of coil diameter on acceptable spacing. North American vehicles have nominal ground clearances of approximately $200 \mathrm{~mm}$ and in Europe and Asia-Pacific this metric may be closer to $150 \mathrm{~mm}$ (Nissan Leaf EV, $\mathrm{z}=160 \mathrm{~mm}$ ). Coil radius is therefore of critical importance in not only vehicle packaging and WPT integration but overall coupling factor and power transfer capability. One can define the approximate limits of coil separation as the point at which the field flux density radial and co-elevation components are identical. Application of this definition in (2) leads to the condition in (3) for the z-axis spacing, d, at which the field becomes progressively more of a flat field and therefore less able to link with the secondary coil window leading to a low coupling coefficient. Note that $\cos (\theta)=\mathrm{d} / \mathrm{r}$ and $\sin (\theta)=\mathrm{a}_{1} / \mathrm{r}$ in this derivation. The need for standardization in WPT coupling coefficient and overall vehicle electrification was discussed in a forum at IEEE's $1^{\text {st }}$ International Electric Vehicle Conference [14].

$$
\frac{\mu_{0} N_{1} I_{1} a_{1}^{2}}{2 r^{3}} \cos \theta=\frac{\mu_{0} N_{1} I_{1} a_{1}^{2}}{4 r^{3}} \sin \theta \stackrel{\text { sub }}{\Rightarrow} 2 \frac{d}{r}=\frac{a_{1}}{r} ; \quad \therefore d \leq \frac{a_{1}}{2}
$$

The conclusion here is that coupling coil spacing should be half the coil radius, or a fourth of its diameter to be effective in WPT charging. To emphasize this fact the coupling coefficient, $\mathrm{k}(\mathrm{z})$, is calculated for a concentric pair of circular current carrying loops according to the procedure given in [15] for mutual flux linked by a secondary coil. After substituting parameters used here into (94-2) of [15] for flux of mutual induction where $a_{1}=$ radius of the primary, $\mathrm{a}_{2}=$ radius of secondary and $\mathrm{N}_{1}$ is the primary turns.

$$
\varphi_{21}=\frac{2 \mu_{0} \pi^{2} a_{1}^{2} a_{2}^{2} N_{1} I_{1}}{\left(a_{1}^{2}+d^{2}\right)^{\frac{3}{2}}}
$$

Primary coil flux in the plane of the coil is difficult to compute and involves solution of elliptic integrals for accurate calculation. In the present situation computation of primary coil flux will rely on (49.12) of [16], commonly known as the Wheeler formula for self-inductance of a current loop where $r_{0}$ is the wire radius. Inductance will then be used to derive the primary coil flux, $\varphi_{11}$. For reference, the self-inductance of a circular current loop is given as (5). Taking the ratio of mutual flux to primary coil flux the result is the relation for coupling coefficient (6).

$$
\begin{aligned}
& L_{11}=N_{1}^{2} \mu_{0} a_{1}\left[\ln \left(\frac{8 a_{1}}{r_{0}}\right)-\frac{7}{4}\right] \\
& k=\frac{\varphi_{21}}{\varphi_{11}}=\frac{2 \pi^{2} a_{1} a_{2}^{2}}{\left(a_{1}^{2}+d^{2}\right)^{\frac{3}{2}}\left[\ln \left(\frac{8 a_{1}}{r_{0}}\right)-\frac{7}{4}\right]}
\end{aligned}
$$

It is also beneficial to use equal diameter primary and secondary coils, or perhaps to consider a secondary coil with somewhat larger diameter than the primary. This can be seen by examining (6) for the variation of coupling coefficient $\mathrm{k}(\mathrm{z}=\mathrm{d})$ versus primary coil radius $\mathrm{a}_{1}$ taking secondary coil radius $\mathrm{a}_{2}$ as a parameter.

Fig. 3 shows that mutual flux becomes a maximum when the primary coil radius $a_{1}$ is approximately $0.25 \mathrm{~m}$ for the specified $\mathrm{d}=0.175 \mathrm{~m}$ gap, a ratio of 2.86 . The interesting finding is that both coils should be at least the same physical size, $\mathrm{a}_{2}=0.25 \mathrm{~m}$, to having a secondary coil of even larger diameter to improve coupling coefficient. 

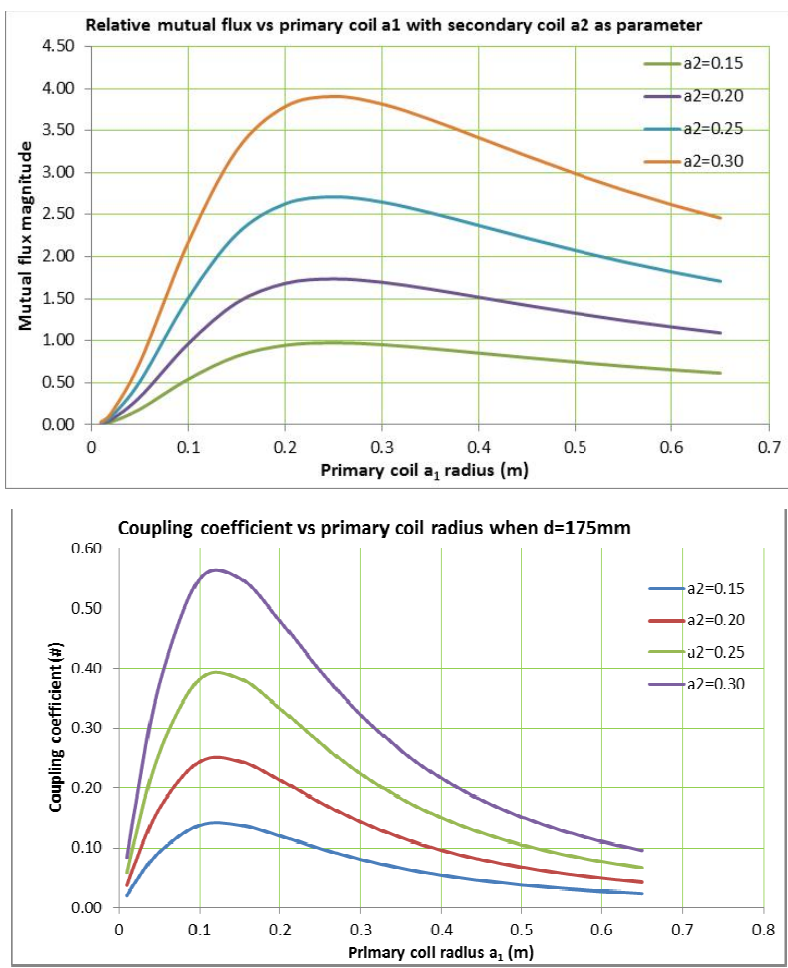

Figure 3. Top: Mutual flux (4), Bottom: coefficient of coupling (6) versus primary coil radius when $\mathrm{d}=175 \mathrm{~mm}$ with secondary coil radius as parameter

\section{B. Sensitivity of Coupling Coefficient with Coil Spacing}

The variation of coupling coefficient with coil spacing, $\mathrm{k}(\mathrm{z})$, is one of the most important variables in WPT charging besides misalignment tolerance. In laboratory tests performed at ORNL an Industrial Electronics model 1500A Powertron amplifier and signal generator are used to apply high current to the primary coil of the coupling coil pair shown in Fig. 2. The equations for coupling coefficient calculation published in [14,17] are repeated here as (7) for open circuit characterization (left) and inductance aiding measurements (right).

$$
k_{o c}(z)=\left.\frac{U_{2}}{U_{1}}\right|_{\substack{U_{1}=U_{o c} \\ \text { gap }=z}} \quad k_{\text {aid }}(z)=\left.\frac{L_{\text {aid }}-\left(L_{1}+L_{2}\right)}{2 \sqrt{L_{1} L_{2}}}\right|_{z}
$$

Open circuit testing makes use of a signal generator and high current amplifier to excite the primary coil at specified sinusoidal current, $I_{1}=10 \mathrm{~A}_{\mathrm{rms}}$ and corresponding potential $\mathrm{U}_{1}\left(\mathrm{~V}_{\mathrm{rms}}\right)$. Measurement of secondary coil potential yields the open circuit voltage sought (7). The ratio is a direct measure of the coupling coefficient, $\mathrm{k}_{\mathrm{oc}}(\mathrm{z})$, at the specified coil spacing. Inductance aiding assessment of coupling coefficient is even more direct, it requires only a single piece of laboratory test equipment such as the Aglient model 34420 LCR meter. The respective coils, primary $L_{1}$ and secondary $\mathrm{L}_{2}$ inductances are measured, then series connected for inductance aiding, $\mathrm{L}_{\text {aid, }}$ at specified gap $\mathrm{z}$. Coupling coefficient $\mathrm{k}_{\mathrm{aid}}(\mathrm{z})$ is then found using (7).

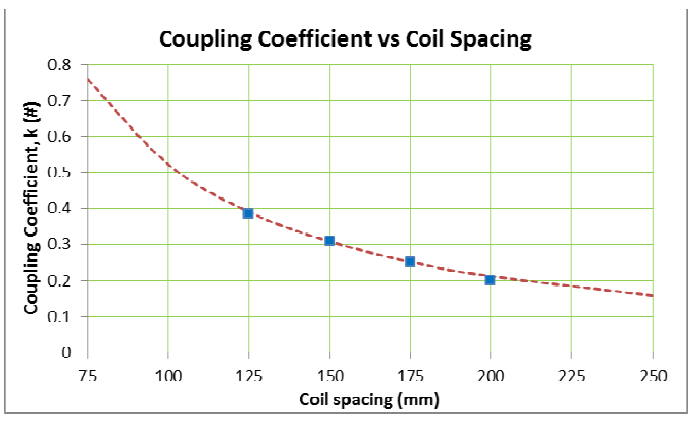

Figure 4. Measured Coupling Coil Coefficient of Coupling, k(z), of coupling coil set shown in Fig. 2 ( $\sim 0.3 \mathrm{~m}$ radius)

Fig. 4 highlights the reciprocal character of coupling coefficient $k(z)$ with gap $z$ over the range of coil spacing of interest for light duty (LD) vehicles. In Fig. 4 the test points are data taken using (7) for both $\mathrm{k}_{\mathrm{oc}}(\mathrm{z})$ and $\mathrm{k}_{\mathrm{aid}}(\mathrm{z})$ on the ORNL coil pair since the data differed only in the $3^{\text {rd }}$ decimal place. The dotted trace is a curve fit to the data points to extrapolate what $\mathrm{k}(\mathrm{z})$ would do outside the interval of interest. Note that by $250 \mathrm{~mm}$ gap that coupling coefficient would drop to approximately 0.15 .

\section{High FREQUENCY POWER INVERTER REGULATION}

Frequency response of the ORNL WPT system depends on the load conditions (i.e., state-of-charge of the battery) and the coupling coefficient (i.e., vehicle coil to primary pad gap and any misalignment between primary and secondary coils). The amount of power transferred to the secondary coil is governed by the switching frequency, duty cycle, and the input voltage of the inverter. For instance, the primary coil voltage can be expressed as (8) where the HF power inverter rail voltage is $U_{d 0}$, pulse duty ratio, $d$, and angular frequency $\omega$.

$$
U_{1}(t)=\frac{4 U_{d 0}}{\pi} \sin \left(d \frac{\pi}{2}\right) \cos (\omega t)
$$

Although the primary coil voltage can be controlled by the active front end converter to vary the dc rail voltage $\mathrm{U}_{\mathrm{d} 0}$, the objective of this study is to dynamically change the switching frequency and the duty cycle in order to achieve the best operating conditions in terms of efficiency and power transfer. In the ORNL laboratory setting the HF power inverter voltage was adjusted using a power supply. Also, in a commercialized version of this WPT technology a dedicated short range communication (DSRC) link as shown in Fig.1 would be needed. The transmitter side of the DSRC collects the measurement data such as battery voltage, battery current, and battery management system (BMS) messages needed for regulation. The grid-side receiver side of the DSRC channel receives this information for control purposes along with supporting primary side measurements. Then, a DSP based embedded control system determines the switching frequency and the appropriate duty cycle according to the control law being used. The switching signals for the inverter IGBTs are generated by 
the DSP control algorithm and applied to the HF power inverter gate drives. The control system can also regulate the inverter power based on the reference power commands that can be received through the V2I communications from a smart grid compliant utility.
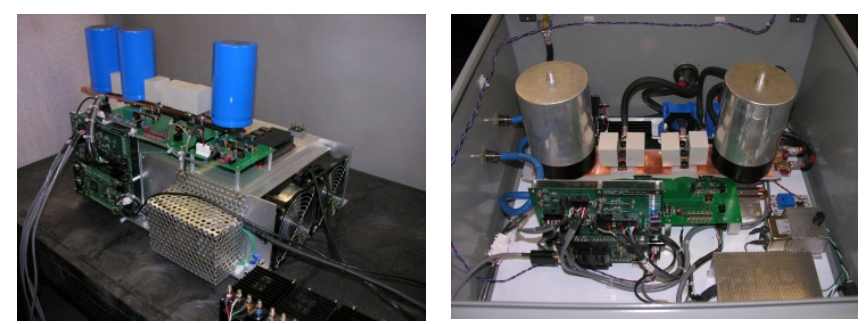

Figure 5. Experimental HF power inverter, open chassis air cooled and packaged with liquid cooling

The ORNL experimental inverter shown in Fig. 5 employs dual Powerex Intellimod IGBTs in an H-bridge arrangement with each phase leg connected to one terminal of the primary coil and tuning capacitor network. The control system of the inverter is implemented within a TMS320F28335PGFA DSP module from Texas Instruments. While generating the switching signals, dead band control, shoot-through prevention, and condition monitoring based protection and termination systems have also been taken into account. For demonstration purposes, the inverter can also be controlled and monitored via RS232 by a host computer. The control system involves instantaneously varying the switching frequency and the duty ratio to adapt to the changing conditions such as battery SOC and the coupling coefficient while taking the efficiency and power transfer level into account.

\section{A. Insertion Loss of Concrete and Bitumen}

Future stationary charge WPT systems, and especially in-motion dynamic wireless power charging applications, will by necessity have the primary coil(s) embedded into parking space concrete or roadway concrete or roadway bitumen (asphalt) surfaces. The insertion loss contributed by the presence of common road surfacing materials in the WPT gap have been characterized for their impact on WPT loss. Fig. 6 illustrates a sample of road surface concrete obtained from scheduled road work on US 95 near Kingston, TN [17]. The concrete is aged and was exposed to traffic for at least 10 years. Insertion loss of materials appears as a loss element in the WPT magnetizing branch.
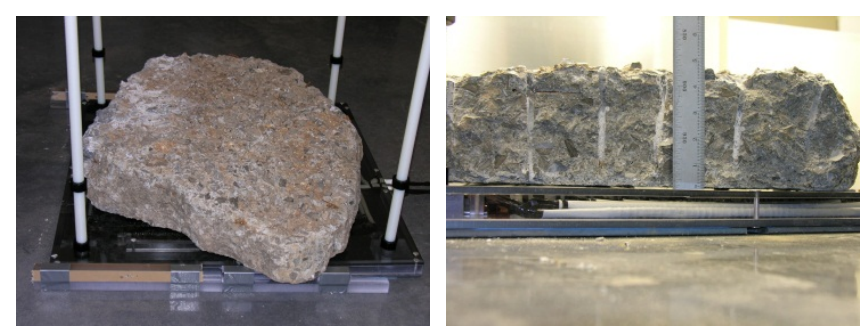

Figure 6. Experimental setup to assess insertion loss of concrete on coupling coil of Fig. 2's performance
The influence of conductive materials such as flux guiding soft ferrites or aluminum shielding in the WPT active zone between primary and secondary coils is to introduce a loss term, $\mathrm{R}_{\mathrm{c}}$, in the magnetizing branch as shown in Fig. 7. Under open circuit conditions the magnetizing branch core loss introduces additional real power to the input that can be computed based on knowledge of the primary coil ac resistance at the test frequency. The results in Table I confirm the change in input phase angle with and without concrete present. The current source, $\mathrm{I}_{1}$, in Fig. 7 represents the Industrial Electronics model 1500A Powertron amplifiers discussed earlier that inject a known and clean $10.00 \mathrm{~A}_{\mathrm{rms}}$ into the primary coil. The system voltages for both open and short circuit conditions are listed in Table I for reference.

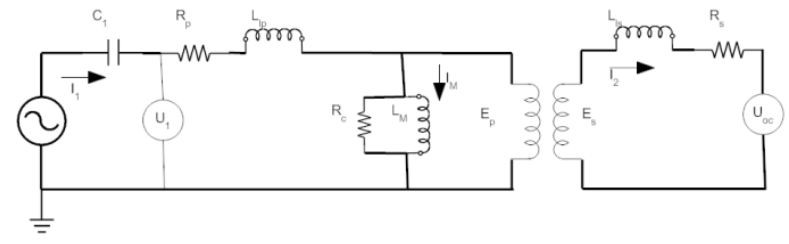

Figure 7. WPT coil pair equivalent circuit having core loss element $R_{c}$

TABLE I. EVAluation OF CONCRETE ON WPT PERformance

\begin{tabular}{|c|c|c|c|c|c|c|}
\hline Conditions & \multicolumn{2}{|c|}{ Primary } & \multicolumn{2}{c|}{ Secondary } & \multicolumn{2}{c|}{ Phase } \\
\hline & $\begin{array}{c}\text { No } \\
\text { concrete }\end{array}$ & $\begin{array}{c}\text { With } \\
\text { concrete }\end{array}$ & No concrete & $\begin{array}{c}\text { With } \\
\text { concrete }\end{array}$ & $\begin{array}{c}\text { No } \\
\text { concrete }\end{array}$ & $\begin{array}{c}\text { With } \\
\text { concrete }\end{array}$ \\
\hline Open Ckt & 51.95 & 50.76 & 10.78 & 9.3 & 88.89 & 88.42 \\
\hline Short Ckt & 49.71 & 48.98 & 0.10 & 0.1 & 89.89 & 88.25 \\
\hline
\end{tabular}

WPT core loss is calculated according to (9) under open circuit conditions (i.e., secondary unloaded) so that core loss resistance, $R_{c}$, can be separated from primary coil series resistance, $R_{p}$ (primary coil resistance, $R_{p}$ in model of Fig. 7). Under short circuit conditions an additional loss term is present due to secondary current flow in that coil yielding results also tabulated in Table 1 . The input current, $\mathrm{I}_{1}$, is regulated so extraction of the coil conductor loss in $R_{p}$ is readily done leaving only determination of $R_{c}$ knowing the phase $\theta$ obtained from the test equipment. The primary coil input power $\left(\mathrm{P}_{\text {in }}\right)$ is given as $(9)$.

$$
P_{\text {in }}=\frac{U_{o c}^{2}}{R_{c}}+I_{1}^{2} R_{p}=U_{1} I_{1} \cos (\theta)
$$

For the experimental coils used the core loss computed from (9) amounts to $6.26 \mathrm{~W}$ without concrete and $13.99 \mathrm{~W}$ with the concrete slab (110 mm thick covering the entire coil window area). The concrete therefore adds $3.93 \mathrm{~W}$ of additional loss under the conditions cited.

\section{B. Inverter Reactive Power due to Variation of $U_{d 0}$ and $d$}

Of particular interest for WPT is the HF power inverter reactive burden due to voltage control of the primary coil in the process of power flow regulation. Experiments were undertaken at ORNL's WPT laboratory to assess inverter reactive power $(\mathrm{Q})$ during variation of duty ratio control when the coils are in full alignment, the gap is fixed and output power $\left(\mathrm{P}_{\mathrm{o}}\right)$ is held constant. In these tests a Chroma model 63210 battery eliminator rated 15/150A, 125/500V, 
$14 \mathrm{kVA}$ is operated in constant voltage (CV) mode at the desired vehicle battery potential. For these tests a different set of coupling coils were used that had been designed for an in-motion WPT charging application of a small battery electric vehicle (a BugE 3 wheeler $36 \mathrm{~V}$ Li-ion). Fig. 8 shows the ORNL "pizza" coils, or 330 coil designs having 7 turns of 6 AWG Litz cable in the primary and 5 turns in the secondary coil. The coils are tuned to $\mathrm{f}_{01}=23 \mathrm{kHz}$ with $\mathrm{L}_{1}=24 \mu \mathrm{H}, \mathrm{C}_{1}=2.0 \mu \mathrm{F}$ and $\mathrm{f}_{02}=21.8 \mathrm{kHz} \mathrm{L}_{2}=18.4 \mu \mathrm{H}, \mathrm{C}_{2}=2.9$ $\mu \mathrm{F}$ with turns ratio, $\mathrm{n}=0.876, \mathrm{R}_{1 \mathrm{dc}}=9.08$ and $\mathrm{R}_{2 \mathrm{dc}}=11.5 \mathrm{~m} \Omega$.

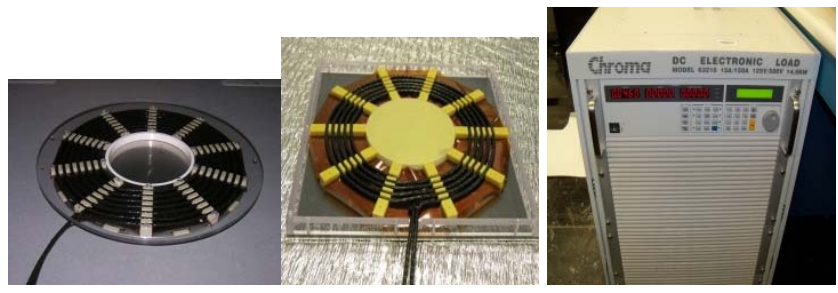

Figure 8. ORNL 330 coil set for inverter $\mathrm{P}$ and $\mathrm{Q}$ assessment to variation of rail voltage $\mathrm{U}_{\mathrm{d} 0}$ and duty ratio $\mathrm{d}$ for constant volt-sec operation

When the small $330 \mathrm{~mm}$ diameter coils are operating at $\mathrm{z}=75 \mathrm{~mm}(\mathrm{D} / \mathrm{z}=4.4)$ and inverter duty $\mathrm{d}=0.8$ with battery potential, $\mathrm{U}_{\mathrm{b}}=80 \mathrm{~V}_{\mathrm{dc}}$, the power transfer peaks at $23 \mathrm{kHz}$ with a load power, $\mathrm{P}_{\mathrm{o}}=2 \mathrm{~kW}$. The test vehicle is a GEM EV with $72 \mathrm{~V}$ lead-acid battery. The real and reactive power levels are shown in Fig. 9 top and primary and secondary coil voltage and currents in Fig. 9 bottom taken at peak power and $\mathrm{f}=23.5 \mathrm{kHz}$.
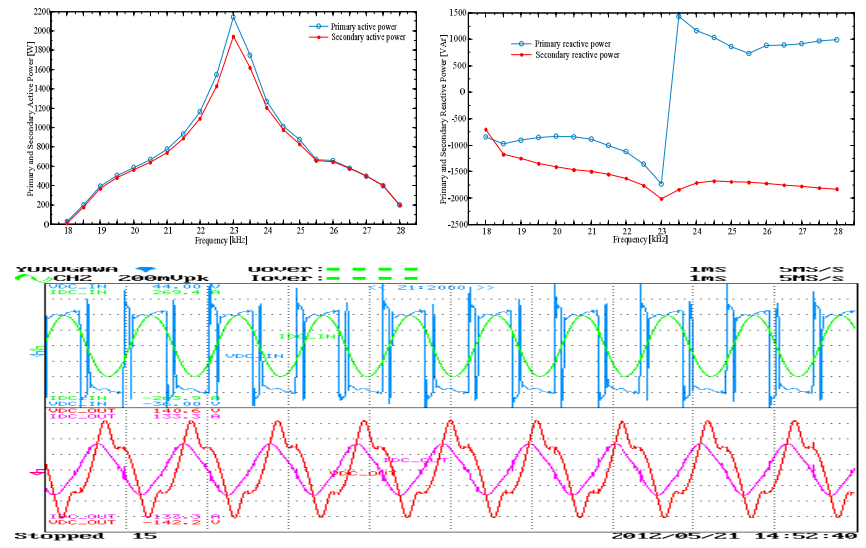

Figure 9. Top: Measured inverter output and secondary P and Q plus Bottom: associated voltage and current waveforms

When the inverter duty ratio is varied the fundamental component of the voltage applied to the primary coil varies according to (8) but the presence of reactive power leads to freewheeling diode conduction in the H-bridge that tends to "fill-in" the inter-pulse dead times shown in the bottom of Fig. 9. It was found that keeping the load power (i.e., power to battery eliminator) constant as duty ratio decreased required a complimentary increase in $\mathrm{HF}$ inverter rail voltage $\mathrm{U}_{\mathrm{d} 0}$. The results are tabulated in Table II. In Table II the heading VSI is the volt-sec-integral applied to the primary coil by the HF power inverter when the respective active switches are $\mathrm{ON}$.

TABLE II. INVERTER UDO-D VARIATION UNDER CONSTANT LOAD

\begin{tabular}{|c|c|c|c|c|c|}
\hline $\boldsymbol{f}$ & $\boldsymbol{U d \boldsymbol { d }}$ & $\boldsymbol{d}$ & $\boldsymbol{V S I}$ & $\boldsymbol{P o}$ & $\boldsymbol{Q}_{\boldsymbol{1}}$ \\
\hline$(\mathrm{kHz})$ & $(\mathrm{Vdc})$ & $(\#)$ & $(\mathrm{mWb})$ & $(\mathrm{W})$ & $(\mathrm{VA})$ \\
\hline 22.5 & 41.87 & 0.8 & 0.743 & 2055 & -2249 \\
\hline 22.5 & 55.26 & 0.6 & 0.736 & 2017 & -3112 \\
\hline 22.5 & 117.66 & 0.4 & 1.18 & 2011 & -7005 \\
\hline
\end{tabular}

Note that in Table II the measured input reactive power, $\mathrm{Q}_{1}$, increases in proportion to the amount that duty ratio, $d$, is decreased while holding output power constant. The implication is that WPT power inverters must therefore have a much higher reactive power rating than real power rating. Similar behavior was shown to be the case by Lee and Lorenz [18] for $\mathrm{MHz}$ wireless coupling over a very large gap with their findings that primary reactive power could be 50 times the input real power and secondary reactive power could reach 10 times the output real power. The authors [19] recognize the issues with high reactive power and recommend measures to address the input reactive power burden the primary puts on the HF inverter. This work then addresses the requirement for WPT systems to implement grid side power factor (PF) correction.

\section{Finite Element Electromagnetics Modeling}

Analysis of coil coupling design by ORNL specialists is being made with CST Microwave Studio using the 3D electromagnetic frequency domain solver. In order to maximize efficiency, low-loss Spectrum Magnetics ferrites $(\mu=3 \mathrm{e} 3, \varepsilon=2 \mathrm{e} 5, \sigma=0.083 \mathrm{~S} / \mathrm{m}$, magnetic $\tan \delta=0.02)$ are employed to increase the inductive coupling coefficient $k$ and to confine the magnetic field to the inter-coil region. Litz wire is used to reduce the ac resistivity of the coils.

In the example geometry shown in Fig. 6, each turn of the 7-turn transmitter/receiver coils is being fed in parallel with the others. The addition of the ferrite yoke (flux guide) increases $k$ from 0.024 to 0.113 for a d=200 $\mathrm{mm}$ coil spacing; for $150 \mathrm{~mm}$ spacing, $k=0.179$. Ohmic dissipation in the primary (transmitter) coil accounts for $87.3 \%$ of the total system losses, with an additional $11.4 \%$ in the $1 / 8$ " aluminum transmitter coil shield; the losses in the ferrites are less than $0.5 \%$ of the total.
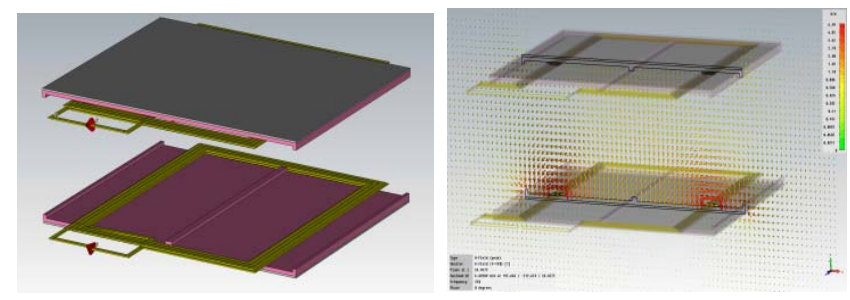

Figure 10. FEA characterization of ferrite plate backed coupling coils (shown in Fig. 2). Left: Coil geometry and 6mm MnZn plates, Right: Hfield plot when $\mathrm{f}=150 \mathrm{kHz}, \mathrm{d}=200 \mathrm{~mm}$ gap 


\section{WPT STATIONARY CHARGE EXPERIENCE AT ORNL}

The previous section described power flow control in a WPT system via variation of $\mathrm{HF}$ inverter rail voltage, $\mathrm{U}_{\mathrm{d} 0}$, and duty ratio modulation, $\mathrm{d}$, of the quasi-square wave primary coil voltage excitation. In this section important fundamentals of WPT are presented that span some of the lessons learned at ORNL during the course of stationary charging research.

- WPT, also referred to as inductive power transfer IPT, relies on the magnetic performance of a loosely coupled transformer (primary and secondary coil set).

- Loose coupling means very high leakage flux.

- High leakage flux results in poor regulation capability of a transformer and places a high reactive power burden on the drive inverter.

- Compensating capacitors on primary and secondary act to "tune out" the high leakage inductance. The most common compensating technique is primary series, $\mathrm{S}$, and secondary parallel, P, or S-P tuning.

- Operating at, or close to, resonance leads to excessive primary current when the secondary coil is not present or not aligned to the primary.

Discussion of the last two points is essential to understanding the basics of WPT. Experimental work done at ORNL's WPT laboratory show that S-P tuning results in a single peak power transfer above resonance, a sharp input PF transition from inductive to capacitive, relatively smooth secondary PF and a very broad coil-coil and input de to output dc efficiency. In contrast, S-S tuning also exhibits a step edged but shallower power transfer peak across the resonant frequency, but a more dramatic PF swing with nearly double the reactive power at the input and modest coil-coil and de input to dc output efficiency. For secondary only S-tuning the power transfer is lower, there are multiple input PF transistions below and above resonance and low efficiency. For these reasons the ORNL system relies on S$\mathrm{P}$ tuning of the coupling coils.

The last bullet point is most significant to WPT control, especially as it applies to HF inverter rail voltage settings. ORNL developed coupling coils for a low voltage BEV (GEM vehicle with $72 \mathrm{~V}$ lead-acid battery pack) that have non-unity turns ratio. Fig. 11 is a modified version of Fig. 7 showing the 1:n turns ratio primary to secondary and having subscripts 1-primary and 2-secondary. The secondary side vehicle RESS pack load reflected from dc to ac variables is shown as $R_{a c}$ and will be discussed later. For a primary fundamental sinusoidal voltage (8) the input current, $I_{1}$, can reach excessive levels when the secondary is absent or when $\mathrm{k}(\mathrm{z})$ is very low, such as $\mathrm{k}(\mathrm{z})<0.15$ or zero. Solving for input current $\mathrm{I}_{1}$ when reflected load $\mathrm{I}_{2}{ }^{\prime}=0$ yields $(10)$.

$$
I_{1}=\left.\frac{\omega C_{1} U_{1}}{\omega C_{1} R_{1}+j\left(\left[\frac{\omega}{\omega_{0}}\right]^{2}-1\right)} \rightarrow \frac{U_{1}}{R_{1}}\right|_{\omega \rightarrow \omega_{0}}
$$

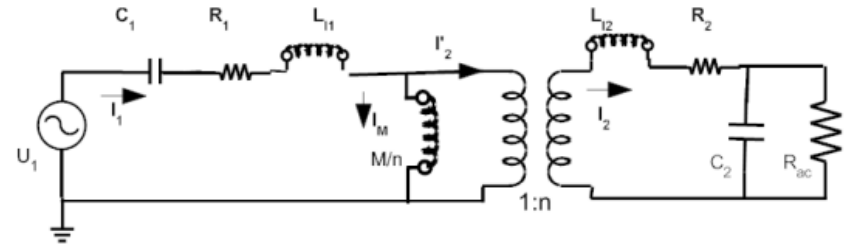

Figure 11. WPT schematic showing coupling coefficient dependent magnetizing branch and non-unity primary-secondar turns ratio, $n$

It is evident by inspection of (10) that the transitions in input PF when excitation frequency is crossing resonance are due to the sign change in the denominator's imaginary part $\left(\left[\frac{\omega}{\omega_{0}}\right]^{2}-1\right)$. Input apparent power, $\mathrm{S}=\mathrm{U}_{1} \mathrm{xI}_{1}$ or in phasor notation, $S=\mathrm{U}_{1} / \underline{0}^{\circ} * \mathrm{I}_{1} / \underline{\theta}$, where $\theta>0^{\circ}$ for $\omega<\omega_{0}$ and lagging PF.

Primary coil resistance, $R_{1}$, at the operating frequency is milli-Ohm value so with even a low source voltage $U_{1}$ the current can over stress the HF inverter semiconductor switches. Therefore, the HF inverter requires desaturation detection or other current limiting means on the power stage to prevent destructive currents from flowing. Tests on the Litz cable wound coupling coils exhibited a power law response of resistance with frequency according to (11) where $\mathrm{f}_{0}=20 \mathrm{kHz}$ is the normalization value of frequency.

$$
R_{1}(f)=R_{1 d c}\left\{1+\frac{1}{12}\left(\frac{f}{f_{0}}\right)^{2}\right\}
$$

\section{A. WPT Lessons Learned Case 1: Secondary Absent}

This is the case already examined and shown to result in (10), a condition of excessive HF power converter current. Essentially, the primary tuning capacitor completely cancels the primary inductance resulting in extreme magnetizing current. Refer to Fig. 11 for the case of non-unity turns ratio leading to the following definitions of primary, $\mathrm{L}_{11}$, and secondary, $\mathrm{L}_{12}$, leakage inductance and mutual inductance, $\mathrm{M}$, noting that $\mathrm{k}(\mathrm{z})<1$. Using (13) the input current $\mathrm{I}_{1}$ for the non-unity turns case in Fig. 11 results again in (10).

$$
\begin{array}{ll}
L_{l 1}=L_{1}-\frac{M}{n} & L_{l 2}=L_{2}-n M \\
M=k(z) \sqrt{L_{1} L_{2}} & n=\sqrt{\frac{L_{2}}{L_{1}}} \\
\omega_{2 L}=\frac{(1-k(z))}{L_{2} C_{2}} & Q_{2}=\omega R_{a c} C_{2}
\end{array}
$$

\section{B. WPT Lessons Learned Case 2: Aligned, no Load}

When the secondary is present and aligned but no load $\left(\mathrm{R}_{\mathrm{ac}}=\infty\right)$ the tuning capacitor, $\mathrm{C}_{2}$, acts to short circuit the secondary leading to current $\mathrm{I}_{2}=\mathrm{I}_{2 \mathrm{sc}}$. In this case the input current I1 becomes excessive as in (10) due to the secondary leakage and tuning capacitor impedance, $Z_{2}$ ', being reflected to the primary and in parallel with the magnetizing branch.

$$
Z_{2}^{\prime}=\frac{R_{2}}{n^{2}}+j \frac{1}{n^{2}}\left[\frac{\left(\frac{\omega}{\omega_{2 L}}\right)^{2}-1}{\omega C_{2}}\right]
$$


This case again shows that in the vicinity of the system resonance, the coupling coefficient dependent lower resonance point $\omega_{2 \mathrm{~L}}$, that input current $\mathrm{I}_{1}$ is at least $\mathrm{U}_{1} /\left(\mathrm{R}_{1}+\mathrm{R}_{2} / \mathrm{n}^{2}\right)$. The only difference now is that 2 resonance conditions interact, primary $\left(\omega / \omega_{0}\right)$ from (10) and $\left(\omega / \omega_{2 \mathrm{~L}}\right)$ from (15).

\section{WPT Lessons Learned Case 3: Aligned with Load}

For the loaded case in Fig. 11 the conditions given in subsection B. are now revised to include a battery load dependent resistance reflected from dc to single phase ac coordinates as (16) where battery voltage is $\mathrm{U}_{\mathrm{b}}$ and power $\mathrm{P}_{\mathrm{o}}$. Using this the derivation (15) is modified to replace element $C_{2}$ with $C_{2}$ in parallel with $R_{a c}$ shown as $Z_{L}$ ' (17).

$$
\begin{aligned}
& R_{a c}=\frac{\pi^{2}}{8} \frac{U_{b}^{2}}{P_{o}} \\
& Z_{L}^{\prime}=\frac{1}{n^{2}}\left[\frac{R_{a c}}{1+Q_{2}^{2}}-j \frac{R_{a c} Q_{2}}{1+Q_{2}^{2}}\right]
\end{aligned}
$$

Input current $I_{1}$ then splits between the magnetizing branch and the secondary branch reflected to the primary such that output power is due to current flowing in the reflected load branch.

\section{CONCLUSION}

Wireless power charging of PEV's is an emerging technology that is finding widespread and rapid appeal as a safe, convenient and flexible means of charging. Simulation and experimental results on coupling coil performance and efficiency are presented that show the close association of coil diameter to separation and the shielding benefits of ferrite backed coils. Lessons learned on WPT by the ORNL team are highlighted showing the strong influence the secondary, especially its absence, has on HF power inverter output current and PF.

\section{ACKNOWLEDGMENT}

The authors with to acknowledge the able assistance of Chester Coomer and Steven Campbell for fabricating the coupling coils and fixtures and P.T. Jones and Paul Chambon for their able assistance in vehicle systems aspects of this program at ORNL's National Laboratory's National Transportation Research Center, in Knoxville, TN.

\section{REFERENCES}

[1] Sungwoo Lee, Jin Huh, Changbyung Park, Nam-Sup Choi, GyuHyeoung Cho, Chun-Taek Rim, "On-Line Electric Vehicle using Inductive Power Transfer System," IEEE Energy Conversion Congress \& Exposition, ECCE2010, Atlanta Hilton Hotel, Atlanta, GA., pgs. 1598-1601, 12-16 Sept. 2010

[2] Yuan-Hsin Chao, Jenn-Jong Shieh, Ching-Tsai Pan, Wei-Chih Shen, Mu-Ping Chen, "A Primary-Side Control Strategy for Series-Parallel Loosely Coupled Inductive Power Transfer Systems," IEEE Conference on Industrial Electronics and Applications, ICIEA2007, Harbin, China, pgs 2322-2327, 23-25 May 2007

[3] Yuan-Hsin Chao, Jenn-Jong Shieh, Ching-Tsai Pan, Wei-Chih Shen, "A Closed-form Oriented Compensator Analysis for Series-parallel Loosely Coupled Inductive Power Transfer Systems," IEEE Power
Electronics Specialists Conference, PESC2007, Orlando, FL, pgs. 1215-1220, 17-21 June 2007

[4] R. Mecke, C. Rathge, "High Frequency Resonant Inverter for Contactless Energy Transmission over Large Air Gap," IEEE Power Electronics Specialists Conference, PESC2004, Aachen, Germany, Vol. 4, pgs. 1737-1743, 20-25 June 2004

[5] Zelijko Pantic, Subhashish Bhattacharya, Srdjan Lukic, "Optimal Resonant Tank Design Considerations for Primary Track Compensation in Inductive Power Transfer Systems," IEEE Energy Conversion Congress \& Exposition, ECCE2010, Atlanta Hilton Hotel, Atlanta, GA., pgs. 1602-1609, 12-16 Sept. 2010

[6] Y. Nagatsuka, N. Ehara, Y. Kaneko, S. Abe, T. Yasuda, "Compact Contactless Power Transfer System for Electric Vehicles," The 2010 International Power Electronics Conference, IPEC2010, Sapporo, Japan, pgs. 807-813, 21-24 June 2010

[7] Fumiaki Nakao, Yoshio Matsuo, Mikio Kitsoka, Siroshi Sakamoto, "Ferrite Core Couplers for Inductive Chargers," IEEE Power Conversion Conference, PCC2002, Osaka, Japan, pgs. 850-854, 2-5 April 2002

[8] Takehiro Imura, Hiroyuki Okabe, Yoichi Hori, "Basic Experimental Study on Helical Antennas of Wireless Power Transfer for Electric Vehicles by using Magnetic Resonant Couplings," IEEE Vehicle Power and Propulsion Conference, VPPC2009, Fairlane Conference Center, Dearborn, MI., pgs. 936-940, 7-10 September 2009

[9] Grant A. Covic, Michael L. G. Kissin, Dariusz Kacprazak, Niels Clausen, Hao Hao, "A Bipolar Primary Pad Topology for EV Stationary Charging and Highway Power by Inductive Coupling," IEEE Energy Conversion Congress \& Exposition, ECCE2011, Hyatt Regency Hotel, Phoenix, AZ, pgs. 1832-1838, 17-22 Sept. 2011

[10] Mickel Budhia, Grant A. Covic, John T. Boys, Chang-Yu Huang, "Development and Evaluation of a Single Sided Flux Couplers for Contactless Electric Vehicle Charging," IEEE Energy Conversion Congress \& Exposition, ECCE2011, Hyatt Regency Hotel, Phoenix, AZ, pgs. 614-621, 17-22 Sept. 2011

[11] Mickel Budhia, Grant A. Covic, John T. Boys, "Design and Optimization of Circular Magnetic Structures for Lumped Inductive Power Transfer Systems," IEEE Transactions on Power Electronics, Vol. 26, No. 11, pgs. 3096-3101, November 2011

[12] H.H. Wu, A. Gilchrist, K.Sealy, P.Israelsen, J. Muhs, "A Review on Inductive Charging of Electric Vehicles," IEEE 2011 International Electric Machines and Drives Conference, IEMDC2011, Niagara Falls, NY, pgs. 866-871, 15-18 May 2011

[13] J.M. Miller, "Wireless Charging of Plug-in Electric Vehicles (PEV's)," IEEE Power Electronics Society (PELs) Digital Media Series, Webinar, 8 December 2011

[14] J.M. Miller, "New Trends in EV's: The Need for Standards," $1^{\text {st }}$ IEEE International Electric Vehicle Conference on (IEVC2012), Greenville, SC, 4-8 March 2012

[15] L. Page, N.I. Adams, Principles of Electricity, first edition, D. Van Nostrand Company, Inc., NY, 1931

[16] R. Becker, Electromagnetic Fields and Interactions, Dover Publications, Inc., Copyright (C) 1964 Blaisdell Publishing Company and Blackie and Son Limited, NY

[17] John M. Miller, Omer Onar, "ORNL's In-motion WPT System," Conference on Electric Roads and Vehicles, CERV2012, Newpark Resort and Hotel, Park City, UT, 16-17 February 2012

[18] Seung-Hwan Lee, Robert D. Lorenz, "A Design Methodology for Multi-kW, Large Airgap, MHz Frequency, Wireless Power Transfer Systems," IEEE $3^{\text {rd }}$ Energy Conversion Congress \& Exposition ECCE2011, Hyatt-Regency Hotel, Phoenix, AZ 17-20 Sept 2011

[19] Michael Pickelsimer, Leon Tolbert, Burak Ozpineci, John M. Miller, "Simulation of an Electric Vehicle Class Wireless Power Transfer System as Viewed from the Power Grid," IEEE International Electric Vehicle Conference, IEVC2012, CU-ICAR, Greenville, SC, 4-8 March 2012

Identify applicable sponsor/s here. U.S. Department of Energy 